\title{
An integrated approach to child psychotherapy with co-parental support: a longitudinal outcome study
}

\author{
Marina Miscioscia, ${ }^{1,2}$ Alessandra Simonelli, ${ }^{2}$ Lorenza Svanellini, ${ }^{1,3}$ Marta Sisti, ${ }^{1}$ Laura Sudati, ${ }^{1}$ Maria Elena Brianda, ${ }^{2}$ \\ Pier Antonio Battistella, ${ }^{1}$ Michela Gatta ${ }^{1,3}$
}

${ }^{1}$ Department of Women's and Children's Health, University of Padua; ${ }^{2}$ Department of Developmental Psychology and Socialisation, University of Padua; ${ }^{3}$ Childhood Adolescence Family Unit, Aulss 6 Veneto, Padua, Italy

\begin{abstract}
Studies about the effectiveness of psychodynamic psychotherapy interventions with children and adolescents suggest potential adverse effects of this treatment when not supported by a parallel work with parents: it seems that it could damage family functioning and affect family balances. This research aims to assess psychopathological outcomes after two years of psychodynamic psychotherapy by comparing two groups $(\mathrm{G})$ of children and adolescents, related to a Childhood Adolescence Family Service: G1 - individual therapy for child/adolescent only; G2 - therapy for child/adolescent and a separate session of co-parenting support. 21 families with children aged between 6 and 17 years completed the entire treatment. The research protocol involves: Lausanne Trilogue Play, Children Behavior Check List and Family Empowerment Scale. Results show a positive effect of the treatment on the child/adolescent psychopathological profile with a significant improvement concerning the reduction of both internalizing and externalizing problems. Results show the effectiveness of the integrated intervention in the improvement of parents' abilities to validate the children emotional state. Our results suggesting that parenting support increase parental sensitivity, helping the parents to become more able to recognize

Correspondence: Michela Gatta, Department of Woman and Child Health, University of Padua, via Giustiniani 3, 35128 Padua, Italy.

the children's emotional state and to validate it.
\end{abstract} Tel.: +39.049.8213506.

E-mail: michela.gatta@unipd.it

Citation: Miscioscia, M., Simonelli, A., Svanellini, L., Sisti, M., Sudati, L., Brianda, M.E., Battistella, P.A., \& Gatta, M. (2018). An integrated approach to child psychotherapy with co-parental support: a longitudinal outcome study. Research in Psychotherapy: Psychopathology, Process and Outcome, 21(2), 63-71. doi: 10.4081/ripppo.2018.297

Contributions: MM analysed the data and drafted a first version of work; she provided a final approval of the manuscript: AS analysed the data, interpretation of results and approved the manuscript. LS, MS, LS, MEB, PAB acquired and analysed the data and approved the final manuscript. MG, study conception and design, data collection and analysis, interpretation of results and write up.

Conflict of interest: the authors declare no potential conflict of interest.

Funding: the broader research project called The Lausanne Trilogue Play use a psycho-diagnostic and therapeutic tool in a Neuropsychiatric Unit: an innovative clinical experience working with psychiatric children and adolescents began in 2012 and was funded by the Italian Ministry of Health (GR-2010- 2318865).

Received for publication: 21 December 2017.

Revision received: 28 May 2018.

Accepted for publication: 28 May 2018.

This work is licensed under a Creative Commons Attribution NonCommercial 4.0 License (CC BY-NC 4.0).

CCopyright M. Miscioscia et al., 2018

Licensee PAGEPress, Italy

Research in Psychotherapy:

Psychopathology, Process and Outcome 2018; 21:63-71

doi:10.4081/ripppo.2018.297
Key words: Lausanne Trilogue play; Psychotherapy; Child outcomes; Family interactions; Co-parenting.

\section{Introduction}

Incidence rates of developmental psychopathology point out the need to enlarge the field of systematic research about the clinical effectiveness of treatments in child and adolescent mental health services. Among psychological therapies, research about psychodynamic psychotherapy reveals its positive effects on a variety of children and adolescents' clinical diagnoses, but it is also one of the least well-funded (Midgley, O'Keeffe, French \& Kennedy, 2017).

The psychodynamic psychotherapy approach refers to the assumption that child's difficulties conceal an inherent logic to the constructing of his earliest relational experiences (Kegerreis \& Midgley, 2014). This therapeutical approach was proved to be effective with children and adolescents with a variety range of mental health problems, and when compared with other approaches, its outcomes traditionally appear to be more sustained throughout the time (Midgley \& Kennedy, 2011). In the current research panorama, Goodyer et al. (2017) observe that short-term psychoanalytical therapy is as effective as Cognitive behavioural therapy and psychosocial intervention in the treatment of adolescents with depression. The improvement associated with the implementation of a psychodynamic psychotherapy involves different aspects, as the general functioning (Edlund, Thorèn \& Carlberg, 
2014), pattern of attachment (Stefini, Horn, Winkelmann, Geise-Elze, Hartmann \& Kronmüller, 2013), and the severity of emotional and behavioural problems (Krischer et al., 2013).

In our professional framework, the psychodynamic psychotherapeutical approach provides for individual clinical sessions with children, working on developmental and adjustment capabilities and mental representation, and parents in separated settings. As evidence of facts, literature emphasizes with the conclusion that no child therapy can be successful without significant changes in family dynamics with a special focus on parents' interpersonal experience (Fonagy \& Target, 1996).

The effectiveness of child's psychotherapy depends considerably on how the environment supports the treatment and how much the treatment is part of the environment (Sutton \& Hughes, 2005). The developmental psychopathology perspective highlights the role and the influence of the quality of family interactions as well as the co-parenting support in infant development (FivazDepeursinge \& Corboz-Warnery, 1999; Teubert \& Pinquart, 2010). It is within the familiar triangular interactions that children develop social abilities in understanding of self-/other differentiation, strengthening the reciprocity and sharing feelings (Fonagy, Gergely, \& Target, 2007; Philipp, Fivaz-Depeursinge, Corboz-Warnery \& Favez, 2009; Stern, 2004).

Along with these evidences, literature attests that including and supporting parenthood, in addition to psychodynamic intervention for the child, represents a crucial factor for children (Gatta et al., 2009; Palmer, Nascimento \& Fonagy, 2013) and adolescents' treatment (Gatta et al., 2011; Gatta et al., 2016). Studies about the effectiveness of psychodynamic psychotherapy interventions with children and adolescents suggest potential adverse outcomes when the treatment is not supported by a parallel work with parents: it seems that it could affect the family balance and functioning (Midgley \& Kennedy, 2011; Midgley, et al., 2017). Furthermore, this parallel work, called psychotherapy of parenthood by Sutton and Hughes, helps parents to care their child, to understand his/her emotional state and behaviour, and to scaffold the child considering his/her developmental stage (Sutton \& Hughes, 2005). The main goal of this psychodynamic therapeutical approach is to provide an experience that focuses on the parent within the parent-child relationship (Siegel \& Hartzell, 2003). Parenthood therapy will be carried out in relation to the here and now, the parent's distress in coping with the child, as well as through a past perspective, which considers the intergenerational transmission, the representations of parent's family of origin and the personality patterns of parents (Oren, 2011).

It is worth to pointing out that recent research is even more interested in clarifying the role of parent-child relationship on the onset of child's emotional and behavioural disturbances, and studying the effectiveness of parent-in- fant psychotherapy in improving parental and infant wellbeing and in fostering functional parent-infant relationship (Barlow, Bennet, Midgley, Larkin \& Way, 2017). Bjørseth and Wichstrøm (2016) investigated the effectiveness of psychotherapy focused on parent-child interactions in young children with behaviour problems, at Child and Adolescent Mental Health Clinics, and demonstrated a greater benefit for those children who received a Parent-Child Interaction Therapy (Eyberg, Nelson \& Boggs, 2008; Thomas \& Zimmer-Gembeck, 2007) compared to the usual treatment.

The psychodynamic approach to parent-infant psychotherapy, during the early infancy, aims to reveal unconscious relationship patterns which can influence the maternal representations and sensitivity and, therefore, infant attachment security (Lieberman, Weston \& Pawl, 1991), usually working. However, parent-infant psychodynamic psychotherapy may be also targeted to either the father or the involvement of both parents. In fact, many studies investigated the impact of father's involvement in the context of parent training (Lundahl, Tollefson, Risser $\&$ Lovejoy, 2008) and supported the efficacy of co-parenting-oriented programs in improving children's emotional and social development (Pruett, Pruett, Cowan \& Cowan, 2017).

A study of Dana Atzil Slonim (Slonim, Shefler, Slonim \& Tishby, 2012) and colleagues investigated whether and how internal representations of adolescents' relationship with their parents changed after one year of treatment and, whether the observed changes were followed by changes in symptomatology. Using qualitative thematic clusters to categorize the internal representations, they found that the Treatment Group, compared to the Community Group, was characterized by higher initial levels in emotionally painful interaction and lower initial levels in close and supportive interaction. Additionally evidence shows that adolescent clinical population report a perception of unhelpfulness relationship with parents and unsupportive parenting (Adams \& Laursen, 2007). However, in so far the literature highlights the internal representations underlying parents and child interactions, and no studies, in our knowledge, observed family interactions in toddler and adolescents at the light of their connection with changes of children's psychopathological symptoms over time.

Regarding the observation of family interactions, recent studies have developed the application of the Lausanne Trilogue Play (LTP) paradigm (Fivaz-Depeursinge \& CorbozWarnery, 1999) in clinical contexts focalize the assessment process on both the parent-parent-child interaction and the co-parenting subsystem. This paradigm assumes that the quality of parent-child interactions varies depending on the presence or absence of the other parent (Gatta, Miscioscia, Brianda \& Simonelli, 2017a). LTP studies confirmed the association between peculiar relational patterns and some traits of developmental psychopathologies, such as emotional difficulties, externalizing and internalizing problems 
(Gatta et al., 2015; Gatta et al., 2017b; Mazzoni, Lavadera, Di Benedetto, Criscuolo \& Mangano, 2015), infantile anorexia (Lucarelli, Ammaniti, Porreca, \& Simonelli, 2017), and autistic spectrum disorder (Mazzoni, Veronesi \& Vismara, 2013). The quality of triadic interactions changes in association with child's medical condition (Gatta et al., 2017c; Pellizzoni, Tripani, Miscioscia, Giuliani, \& Clarici, 2017), and can promote better child outcomes in situations of parental psychopathology and dyadic parent-child dysfunctional interactions (Tissot, Favez, Frascarolo \& Despland, 2016).

Given the above considerations, in 2012 we started a longitudinal research project based on the cooperation between the Mental Health Unit for Children and the University of Padua. The project aimed first to understand the feasibility of the LTP paradigm within the diagnostic assessment (Gatta et al., 2017a), and second to evaluate the effectiveness of an integrated treatment that add, to the individual psychotherapy for children/adolescents, the parental support. In a preliminary report, we analysed the clinical effectiveness of one-year treatment considering child's symptoms and quality of family's interactions. A noteworthy reduction of internalising symptoms resulted, while the quality of family's interactions seems to remain stable after one-year treatment (Gatta, Sisti, Sudati, Miscioscia, \& Simonelli, 2016).

As an extension of this preliminary report, this research investigated the outcomes of a two-years (T24 = 24 months). The aim was to determine whether this integrated treatment can lead to better children/adolescents' outcomes, higher quality of family interactions, and parents' perception of parental empowerment. We wondered if a two-year psychodynamic integrated treatment (therapy for child/adolescent plus a separate session of co-parenting support) could improve child outcomes in contrast to a standard individual treatment.

In light of the literature background we hypothesized that an integrated approach to child psychotherapy with co-parental support allows to: i) favourable outcome of children/adolescents' psychopathological behaviours and symptomatology; ii) a significant change in the quality of family interactions and parents capacities to scaffold the children/adolescents and validate their emotional state. Moreover, we hypothesized also iii) that a co-parenting support helps parents to improve parents' perception of parental empowerment. With regard to the child and adolescent' treatment, we assume that the family system must be able to change along with the child, in order to assure outcome stability.

\section{Materials and Methods}

\section{Methods}

In this paper, we present the outcome of a longitudinal clinical research called The Lausanne Trilogue Play used as psychodiagnostic and therapeutic tool in the Neuropsychiatric Unit: an innovative clinical experience working with psychiatric children and adolescents carried out in a Public Mental Health Service for child, adolescent and families in North Italy. The entire research protocol (Ethical-Committee approval CEP 204 SC) - enrollment, test, treatment, retest, follow up - meant to be administrated to families with children aged between 4 and 17 years which asked for a psycho-diagnostic assessment due to emotional and/or behavioural child problems.

Participants underwent a diagnostic assessment consisting of clinical interviews, self and proxy-report questionnaires, and the LTP. Clinicians were enrolled in the research project, taking part in the data acquisition. At the end of the diagnostic assessment, in a specific and separate appointment, clinician explains the research project and the protocol asking parents to sign an informed consensus approved by the ULSS6 committee. When families were enrolled, they were divided into two groups: the first group (G1) was provided with psychotherapy for the child/adolescent, while the second group (G2) was provided with psychotherapy for the child associated with coparenting support. Clinician proposes to family one of the two different psychotherapeutic treatments, depending on the global diagnostic evaluation.

Specifically, the intervention was characterized by a long-term treatment (80 sessions) with weekly 45-minute psychodynamic sessions for children/adolescents and a fortnightly 60 -minute co-parenting support session for parents (40 sessions).

\section{Participants}

31 families were enrolled over a period of 8 months, of whom 21 families completed the entire therapeutic intervention lasting 24 months. The group of 10 families who did not complete the two-year treatment presented a heterogeneous profile. Between them, seven families drop-out the treatment, two families with divorced parents showed high couple conflict, which hindered the continuity of the treatment and then they were excluded from this study. Finally, one family move out of the Region. The total sample then consists of 21 children and adolescents aged 6-17 years (mean age $=11.48, \mathrm{D}=3,25), 8$ males $(47.8 \%)$ and 13 females $(52.2 \%)$, and their parents (mean age of mothers $45.32, \mathrm{SD}=5.5$; mean age of father 49.86 , $\mathrm{SD}=4.9)$. In Figure 1 the ICD-10-CM Children Diagnosis are presented.

The clinicians, who have conducted the diagnostic assessment, assigned children and parents to one of two conditions: $n=10(47,6 \%)$ were assigned to the condition $\mathrm{G} 1$, and $n=11(52,4 \%)$ were assigned to the condition $\mathrm{G} 2$ (Figure 1).

\section{Materials}

The research protocol involves the Lausanne Trilogue 
Play, the Child Behaviour Check List (CBCL)/6-18, and the Family Empowerment Scale.

Child Behaviour Check List (Achenbach \& Rescorla, 2001). The CBCL is one of the most commonly used scales for rating juvenile behaviour, adopted internationally in the clinical setting and in research. It is a questionnaire (report form) that is completed by parents (referring to the last six months of their child's life), and it has been translated and validated for Italians too (Frigerio et al., 2006). For the purposes of the diagnostic assessment, parents were asked to complete the CBCL questionnaire together. Clinicians asked parents to compare between them their observations about the child behaviour, in order to reach a common perspective of the behaviour. The answers yield a profile of behavioural and emotional problems on eight specific syndrome scales relating to various psychopathological pictures, i.e. anxiety/depression, withdrawal, somatization, social problems, thought-related problems, attention problems, aggressive and role-breaking behaviour. The problems are grouped into: internalizing problems (anxiety/depression, withdrawal, somatization); externalizing problems (aggressive and role-breaking behaviour); and other problems (social problems, thought-related problems, attention problems). These three problem scales are grouped into a total problems scale. There is also a scale based on DSM-oriented diagnostic categories: affective problems; anxiety problems; somatic problems; attentional deficit/hyperactivity problems; oppositional/defiant problems; and behavioural problems. Scores for each scale and subscale are categorized with specific cut-offs that place the child's symptoms on one of three levels: normal, borderline or clinical.

Lausanne Trilogue Play (Fivaz-Depeursinge \& Corboz-Warnery, 1999): it is a semi-standardized procedure for observing the quality of the interactions in fathermother-child systems in a situation in which participants play a game together. The activity is divided into four parts corresponding to four triangles that three people interacting with one another can form. In Part I, one of the two parents interact with the child and the other acts simply as a third-party observer (configuration 2+1). In Part II, the parents' roles are reversed so that the parent who previously interacted with the child acts as an observer,

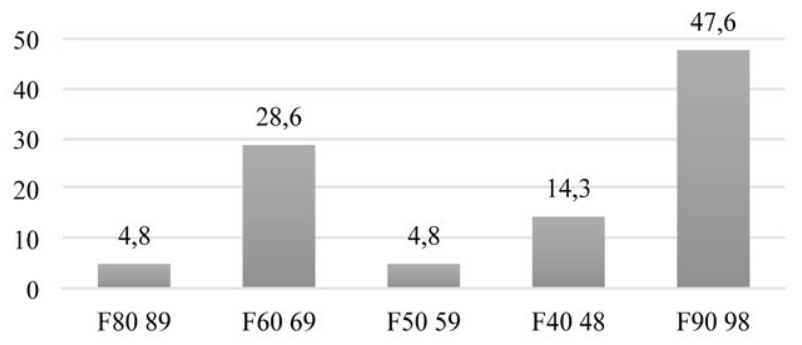

Figure 1. ICD-10-CM children diagnosis. while the other parent plays with the child (configuration $2+1)$. In Part III, both parents interact together with the child; in this case, the parents are seated symmetrically in relation to the child and they have the same role (configuration 3). In Part IV, the parents talk together while the child acts as a third-party observer (configuration 2+1).

The setting involves a round table and three chairs. The two chairs where the parents sit are placed in relation to the child chair so as to form an equilateral triangle (an arrangement considered ideal for facilitating their interactions).

The procedure is coding according to the Family Alliance Assessment Scale manual (FAAS 6.3) (Lavanchy Scaiola, Favez, Tissot, \& Frascarolo); a specific setting for the adolescence age was predisposed (Ballabio, Pantè, \& Destro, 2009; Parolin, Sudati, Gatta, \& Simonelli, in press). These involve two coding approaches, one for the overall procedure and one for each part. Scores are attributed on a three-point Likert scale $(1=$ inappropriate; $2=$ partially appropriate; $3=$ appropriate; $0=$ if the part was not done) for 15 variables.

The criteria used in attributing the scores relate to the frequency and duration of a given behaviour on the part of the participants during the activity. After viewing the whole video-recording, a global score is assigned to each LTP variable in relation to the activity as a whole. Then each part of the video is seen again and scores are attributed to the variables for each separate part (Simonelli, Parolin, Sacchi, De Palo \& Vieno, 2016). The sum of the scores attributed to each variable generates three types of total score: a total for each part of the procedure, obtained from the sum of the scores for the variables within each part; a total for each variable, obtained from the sum of the scores for a given variable (e.g. posture) in all the four parts of the LTP; a total LTP score, obtained from the sum of the subtotals for the four parts (the score can range from 60 to 180). In this study we use the global score and the sum of each part; the LTP videotapes were coded by two adequately-trained independent judges who achieved an overall consistency calculated using Cohen's kappa of .90.

Family Empowerment Scale (FES) (Koren, De Chillo, \& Friesen, 1992): This is a brief questionnaire designed to assess family members' perceptions of empowerment. The 34 FES items tap into two dimensions of family empowerment: level of empowerment (family, service system, community/political); and how empowerment is expressed (attitudes, knowledge, behaviour). Given the focus of the study, only the family subscale (12 items) that refers to the parents' management of everyday situations was used. Answers are given on a Likert scale and range from never (1) to very often (5). Total scores range from 12 to 60 , and there is no cut-off.

\section{Statistical analysis}

Descriptive statistics for both the Groups was performed. In order to observe the evolution of child/adoles- 
cent's psychopathology after two years of treatment, Wilcoxon test (with correction of Bonferroni Post-Hoc) was implemented to compare the two groups' outcomes and to verify significant change at the end of psychotherapy, and across time.

\section{Results}

Before starting treatment, more than $70 \%$ of the entire group of research participants show CBCL scores exceeded the cut-off point ( $\mathrm{T}$ score $>65$ ). Figure 2 shows the group distribution for internalizing, externalizing and total problems scales.

Preliminary analyses have been performed in order to test if there were any statistical differences in the level of child psychopathology at T0. By the comparison of the two groups no significant results have been highlight.

In order to observe the evolution of child/adolescent's psychopathology after two years of treatment, Wilcoxon test (with correction of Bonferroni Post-Hoc) was performed showing a significant clinical improvement at the end of psychotherapy for both internalizing $(Z=-2.638$, $\mathrm{p}=.008)$ and externalizing problems $(\mathrm{Z}=-2.854, \mathrm{p}=.004)$. Table 1 shows the CBCL scores in the two groups (G1 and G2) at T0 and T24. Looking at the means of CBCL scores between $\mathrm{T} 0$ and $\mathrm{T} 24$, we observed a significant score decrease in the two groups and all of three CBCL scales .

With regards to the quality of family interactions, Table 2 shows the means of LTP scales scores at T0 and T24 forG1 (group with weekly psychotherapy for the child) and G2 (psychotherapy for the child and fortnightly section of co-parenting support).

Analyses have been performed according to the differentiation between G1 and G2. Regarding G1, the changes emerged for the variables Co-construction $(\mathrm{z}=-$ $2.000 ; \mathrm{p}=.046)$ and Interactive mistakes during activities $(\mathrm{z}=-2.121 ; \mathrm{p}=.034)$ who were not supported by the correction of Bonferroni.

Regarding G2, a significant increase had been observed after two years of treatment in two of the fifteen variables of the LTP: for the variable Interactive mistakes during transitions $(\mathrm{z}=-2.333 ; \mathrm{p}=.020)$ means show an improvement from 2.2 to 2.8; for the variable Validation of children's emotional state $(\mathrm{z}=-2.449 ; \mathrm{p}=.014)$ means displayed an increase from 1.4 to 1.9. No significant change has been obtained in the global score.

As regard to Family Empowerment, no significant results have been observed from both mother and father FES scores. Looking at the means in Table 3, it is possible to observe that mothers and fathers belonging to $\mathrm{G} 1$ report a decrease from T0 to T24; vice versa G2's mothers and fathers report a little upgrade from $\mathrm{T} 0$ to $\mathrm{T} 24$.

At $\mathrm{T} 0$, we observe that $\mathrm{G} 1$ and $\mathrm{G} 2$ are distinguishable by the functioning of the parental/familiar context $(\mathrm{G} 2<\mathrm{G} 1)$, leading to an intervention predominantly centered on the child (G1) or on both child and parents (G2).

Table 1. Means and SD of Children Behavior Check List scores at $\mathrm{T} 0$ and $\mathrm{T} 24$.

\begin{tabular}{llccccc}
\hline & & \multicolumn{2}{c}{ T0 } & & T24 & \\
& & N & Mean & SD & Mean & SD \\
\hline G1 & Internalizing Problems & 10 & 67.5 & 5.9 & 61.5 & 9.6 \\
\hline \multirow{2}{*}{ Externalizing Problems } & 10 & 60.0 & 9.1 & 54.3 & 7.2 \\
\hline \multirow{2}{*}{ Total Problems } & 10 & 66.8 & 4.9 & 59.4 & 7.5 \\
\hline G2 & Internalizing Problems & 11 & 69.5 & 8.5 & 65.2 & 10.5 \\
\hline \multirow{2}{*}{ Externalizing Problems } & 11 & 67.0 & 8.6 & 61.7 & 9.1 \\
\hline & Total Problems & 11 & 70.9 & 6.5 & 65.4 & 9.6 \\
\hline
\end{tabular}

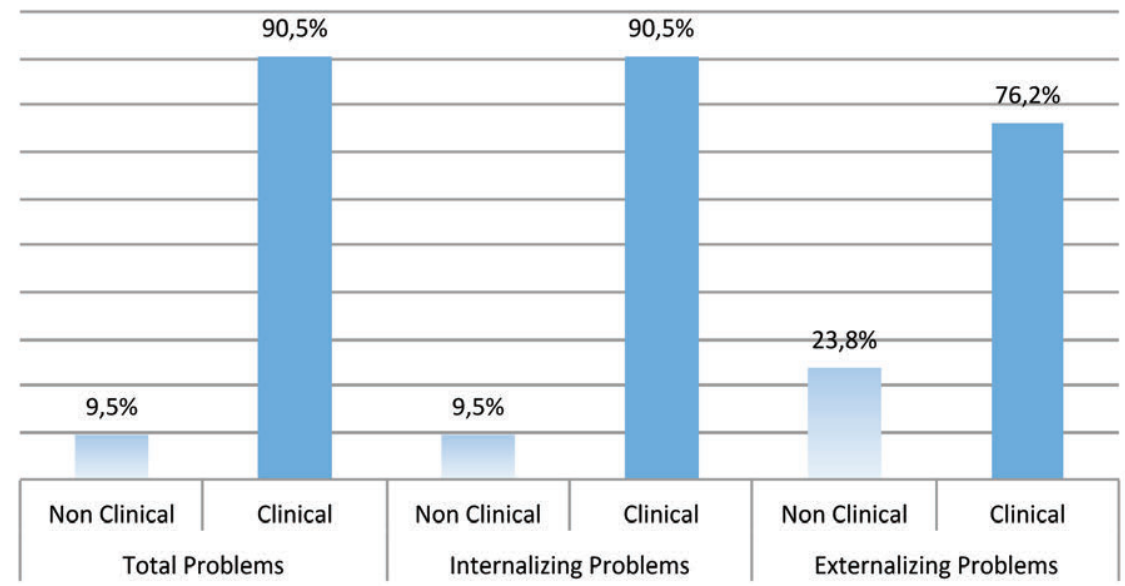

Figure 2. Distribution of Child Behaviour Checklist Scores (at T0). 


\section{Discussion and Conclusions}

The present study aimed to observe the effect of a twoyear psychodynamic and integrated treatment on children and adolescents at the Childhood Adolescence Family Service. In specific we wondered if a two-year psychodynamic integrated treatment (therapy for child/adolescent plus a separate session of co-parenting support) could improve child outcomes compared to a standard individual treatment with children/adolescent.

We hypothesized that an integrated approach to child psychotherapy promote to more favourable outcome in terms of patient's psychopathological behaviours and also of the quality of global family interactions.

In our preliminary study, that differed from the present study for the duration of treatment, we found a significant improvement in children with internalizing problems but not with the externalizing ones (Gatta et al., 2016). Evidence in literature shows that children with emotional or internalizing disorders have more benefit from short-term psychodynamic psychotherapy than children with disruptive or externalizing disorders (Midgley et al., 2017).

The latter result seems to be reached in this study; chil- dren with externalizing problems reach a significant reduction of symptomatology after two-year of treatment. Furthermore, patients with externalizing problems seem more likely to drop out from psychodynamic treatment (Midgley et al., 2017) and need more time to be engaged, to reach setting stability and benefit during the psychodynamic treatment. This seems to be verified from this research.

The present study add new evidences on the effectiveness of psychodynamic integrate treatment with children and adolescents with a two-year treatment evaluation. Moreover, it shows the research experience of an Italian Public Mental Health Service for child, adolescents and their families.

We found that a significant reduction of internalizing and externalizing problems have been observed in all children/adolescent independently of the treatment condition.

As regards of quality of family interactions, results showed an improvement in the G2 group. Parents improved on validation of children's emotional state suggesting that parenting support increase parental sensitivity, helping the parents to become more able to recognize the children's emotional state and to validate it. At the same time, parenting support helps parents to be

Table 2. Means and SD of Lausanne Trilogue Play scales at T0 and T24.

\begin{tabular}{|c|c|c|c|c|c|c|c|c|}
\hline & $\begin{array}{c}\text { T0 } \\
\text { G1 } \\
\text { Mean }\end{array}$ & SD & $\begin{array}{c}\text { G2 } \\
\text { Mean }\end{array}$ & SD & $\begin{array}{c}\text { T24 } \\
\text { G1 } \\
\text { Mean }\end{array}$ & SD & $\begin{array}{c}\text { G2 } \\
\text { Mean }\end{array}$ & SD \\
\hline Part_1 & 34.5 & 3.8 & 30.4 & 4.0 & 33.2 & 5.1 & 32.7 & 3.8 \\
\hline Part_2 & 33.7 & 3.6 & 26.1 & 3.9 & 33.4 & 5.2 & 31.7 & 5.1 \\
\hline Part_3 & 34.4 & 4.4 & 27.3 & 6.3 & 32.4 & 6.3 & 30.3 & 4.9 \\
\hline Part_4 & 34.4 & 4.0 & 26.1 & 7.8 & 31.9 & 6.1 & 28.5 & 5.1 \\
\hline Postures and gazes & 2.3 & 0.7 & 1.6 & 0.5 & 2.2 & 0.6 & 1.8 & 0.6 \\
\hline Inclusion of partners & 2.2 & 0.8 & 2.1 & 0.8 & 2.7 & 0.5 & 2.6 & 0.7 \\
\hline Role implication & 2.0 & 0.7 & 2.1 & 0.7 & 2.0 & 0.9 & 2.0 & 0.9 \\
\hline Structure & 1.8 & 0.7 & 1.4 & 0.7 & 1.3 & 0.5 & 1.0 & 0.0 \\
\hline Co-construction & 1.8 & 0.6 & 1.4 & 0.7 & 1.4 & 0.5 & 1.6 & 0.7 \\
\hline Parental scaffolding & 2.2 & 0.6 & 1.7 & 0.6 & 1.7 & 0.8 & 1.8 & 0.8 \\
\hline Support & 2.3 & 0.5 & 2.1 & 0.7 & 2.1 & 0.6 & 2.5 & 0.5 \\
\hline Conflicts & 2.7 & 0.5 & 2.1 & 0.7 & 2.1 & 0.7 & 2.2 & 0.6 \\
\hline Involvement & 2.5 & 0.5 & 1.6 & 0.7 & 2.7 & 0.5 & 1.9 & 0.8 \\
\hline Self-regulation & 2.5 & 0.5 & 1.4 & 0.5 & 1.9 & 0.7 & 1.7 & 0.6 \\
\hline Interactive mistakes during activities & 1.8 & 0.6 & 1.3 & 0.5 & 1.2 & 0.4 & 1.3 & 0.5 \\
\hline Interactive mistakes during transitions & 2.3 & 0.7 & 2.2 & 0.6 & 2.4 & 0.7 & 2.8 & 0.4 \\
\hline Warmth & 2.1 & 0.6 & 1.6 & 0.7 & 1.5 & 0.7 & 1.4 & 0.5 \\
\hline Validation & 2.2 & 0.6 & 1.4 & 0.5 & 2.0 & 0.7 & 1.9 & 0.5 \\
\hline Authenticity & 2.8 & 0.4 & 2.4 & 0.8 & 2.4 & 0.7 & 2.5 & 0.7 \\
\hline Total Score & 33.3 & 4.1 & 25.1 & 4.8 & 28.8 & 5.7 & 28.7 & 4.4 \\
\hline
\end{tabular}


mutually supportive and to manage their interactive turns more efficiently with the children managing better the transitions between the four LTP parts. Such parent's emotional and behavioural improvement presumably promote the children's healthy change over time. Conversely the families of child/adolescent who underwent to the individual psychotherapy, without parental support showed a loss of quality of triadic interactions. In specific, we found that families without parental support showed low level of Co-Construction and a greater difficulty to repair (Tronick \& Cohn, 1989) Interactive mistakes during activities. This variable refers to the ability of the family to build a shared activity during the interaction, respecting the turns and cooperating to the realization of the common task. Speaking of which, what Favez, Scaiola, Tissot, Darwiche and Frascarolo (2011) affirmed while the construction of the LTP coding system: "one of the fundamental aspects of the flow of the interaction is the ability to fix and readjust the inevitable interactional "mistakes" ( $\mathrm{p}$. 31). Authors insist on the word "inevitable", by suggesting the importance to repair interactional mistakes rather than avoiding them.

In line with literature (Sutton \& Hughes, 2005; Midgley \& Kennedy, 2011), our results could mean that the children's improvement, when not associated with a parental support, would needs more time to be assimilate into the family system. Following this suggestion, even when the family system is not very compromised or when a functional parenting is initially observed, a clinical follow up could be contemplated by the clinician in order to witness the change in the children's wellbeing.

From a qualitative point of view, our funding reveal a general improvement in the LTP scores and eleven of fifteen variables rise up over time. Despite not reaching the statistical significance the observe LTP increment, this suggestion cannot be disregarding for future direction of work. This underline also the strength of the LTP paradigm which is not limited to a single score with a cut-off; the assessment of family interactions require a carefully reasoned analysis with different level and constructs who interact with one another.

A regard of family empowerment, it been observed a qualitative improvement in parents who have followed a co-parenting support. Even in this case, the improvement

Table 3. Means and SD of Family Empowerment Scale scores at T0 and T24 for Mothers and Fathers.

\begin{tabular}{llcccc}
\hline & & $\begin{array}{c}\text { T0 } \\
\text { Mean }\end{array}$ & SD & $\begin{array}{c}\text { T24 } \\
\text { Mean }\end{array}$ & SD \\
\hline G1 & Mothers & 49.1 & 3.8 & 45.9 & 3.5 \\
\hline & Fathers & 44.4 & 3.8 & 43.2 & 2.7 \\
\hline G2 & Mothers & 42.4 & 6.6 & 45.2 & 3.9 \\
\hline & Fathers & 44.3 & 7.1 & 45.2 & 5.4 \\
\hline
\end{tabular}

could ask more time to be well-framed, probably receiving reassurances from the stable improvement of the child/adolescent.

Finally, the use of LTP to evaluate the effectiveness of the integrated therapeutic intervention has proven to be very useful. The LTP could be useful in the clinical practise, for example using Video feedback intervention. Monitoring the course of the family interactions during the psychotherapy helps the clinicians to better focus the coparenting support on the dysfunctional patterns and to better understand what makes stable the changing and to better the follow family system re-adjustment over time.

Research on this topic needs to in-depth analysis and a more systematic methodology (i.e. the addition of a control group and a more consistent sample), which represents the two main limits of our study.

\section{References}

Achenbach, T.M., \& Rescorla, L.A. (2001). Manual for the ASEBA School-Age Forms \& Profiles. Burlington, Vermont: University of Vermont, Research Center for Children, Youth, \& Families.

Adams, R.E., \& Laursen, B. (2007). The correlates of conflict: Disagreement is not necessarily detrimental. Journal of Family Psychology, 21, 445-458. doi: 10.1037/08933200.21.3.445

Aliprandi, M.T., Pelanda, E., \& Senise, T. (2004). Psicoterapia breve di individuazione. La metodologia di Tommaso Senise nella consultazione con l'adolescente. Milan: Feltrinelli.

Ballabio, M., Pantè, S., \& Destro, S (2009). Tossicodipendenza in adolescenza. La trama delle interazioni familiari. In Proceedings of the Symposium National Congress of AIP, Chieti, Italy, September 2009.

Barlow, J., Bennett, C., Midgley, N., Larkin, S.K., \& Wei, Y. (2017). Parent-infant psychotherapy for improving parental and infant mental health. BJPsych Advances, 23, 216-216. doi: 10.1192/apt.23.4.216

Bjørseth, Å., \& Wichstrøm, L. (2016). Effectiveness of ParentChild Interaction Therapy (PCIT) in the Treatment of Young Children's Behaviour Problems. A Randomized Controlled Study. PLoS One, 11, 1-19. doi: 10.1371/journal.pone.0159845

Edlund, J.N., Thorén, A., \& Carlberg, G. (2014). Outcome of psychodynamic child psychotherapy in routine practice. $E u$ ropean Journal of Psychotherapy and Counselling, 16, 22844. doi: 10.1080/13642537.2014.927381

Eyberg, S.M., Nelson, M.M., Boggs, S.R. (2008). Evidence-based psychosocial treatments for children and adolescents with disruptive behavior. Journal of Clinical Child \& Adolescent Psychology, 37(1), 215-37. doi: 10.1080/15374410701820117.

Favez, N., Scaiola, C.L., Tissot, H., Darwiche, J., \& Frascarolo, F. (2011). The Family Alliance Assessment Scales: Steps toward validity and reliability of an observational assessment tool for early family interactions. Journal of Child and Family Studies, 20, 23-37. doi: 10.1007/s10826-010-9374-7.

Fivaz-Depeursinge, E., \& Corboz-Warnery, A. (1999). The primary triangle: A developmental systems view of fathers, mothers, and infants. New York: Basic books.

Fonagy, P., \& Target, M. (1996). Predictors of outcome in child psychoanalysis: a retrospective study of 763 cases at the 
Anna Freud Centre. Journal of the American Psychoanalytic Association, 44, 27-77.

Fonagy, P., Gergelgy, G., \& Target, M. (2007). The parent-infant dyed and the construction of the subjective self. Journal of Child Psychology and Psychiatry and Allied Disciplines, 48(3-4), 288-328.

Frigerio, A., Cozzi, P., Pastore, V., Molteni, M., Borgatti, R., \& Montirosso, R. (2006). La valutazione dei problemi emotivo comportamentali in un campione italiano di bambini in età prescolare attraverso la Child Behavior Checklist e il Caregiver Teacher Report Form. Infanzia e Adolescenza, 5, 24-32.

Gatta, M., Balottin, L., Dal Col, L., Testa, L., Costantino, P., Spoto, A., \& Battistella, P. A. (2016). Long-term effectiveness of multimodal outpatient intervention and treatment in the family setting for adolescents with psychiatric disorders. Minerva Psichiatrica, 57, 51-61.

Gatta, M., Dal Zotto, L., Nequinio, G., Del Col, L., Sorgato, R., Ceranto, G., \& Battistella, P. A. (2011). Parents of adolescents with mental disorders: Improving their caregiving experience. Journal of Child and Family Studies, 20, 478-490. doi: 10.1007/s10826-010-9415-2

Gatta, M., Miscioscia, M., Brianda, M.E., \& Simonelli, A. (2017a). Assessment and intervention in mental health services for children and adolescents using the Lausanne Trilogue Play. Clinical Neuropsychiatry, 14, 216-225.

Gatta, M., Miscioscia, M., Simonelli, A., Sudati, L., Sisti, M., Comis, I., \& Battistella, P.A. (2017b). Contribution of analyses on triadic relationships to diagnostics and treatment planning in developmental psychopathology. Psychological Report, 120, 290-304. doi: 10.1177/0033294116688454

Gatta, M., Miscioscia, M., Svanellini, L., Brianda, M.E., Guerra, G., Battistella, P.A., \& Simonelli, A. (2017c) Triadic interactions in families with preterm children: A comparative study with children born at term. Neuropsychiatric Disease and Treatment, 13, 1-14.

Gatta, M., Ramaglioni, E., Lai, J., Svanellini, L., Toldo, I., Del Col, L., \& Battistella, P. A. (2009). Psychological and behavioral disease during developmental age: The importance of the alliance with parents. Neuropsychiatric Disease and Treatment, 5, 541-546. doi: https://doi.org/10.2147/NDT.S5880

Gatta, M., Simonelli, A., Sudati, L., Sisti, M., Svanellini, L., Stucchi, M., \& Battistella, P. A. (2015). Emotional difficulties in adolescence: psychopathology and family interactions. International Neuropsychiatric Disease Journal, 4, 47-54. doi: 10.9734/INDJ/2015/17789

Gatta, M., Sisti, M., Sudati, L., Miscioscia, M., \& Simonelli, A. (2016). The Lausanne Trilogue Play within the outcome evaluation in infant mental health: a preliminary report. Research in Psychotherapy: Psychopathology, Process and Outcome, 19(1), 19-30. doi: 10.4081/ripppo.2016.198

Goodyer, I.M., Reynolds, S., Barrett, B., Byford, S., Dubicka, B., Hill, J., Holland, F., (...), Fonagy, P. (2017). Cognitive behavioural therapy and short-term psychoanalytical psychotherapy versus a brief psychosocial intervention in adolescents with unipolar major depressive disorder (IMPACT): a multicentre, pragmatic, observer-blind, randomised controlled superiority trial. The Lancet Psychiatry, 4(2), 109119. doi: https://doi.org/10.1016/S2215-0366(16)30378-9

Kegerreis, S., \& Midgley, N. (2014). Psychodynamic approaches. In Pattinson, S., Robson, M., \& Beynon, A. (Eds.), The Handbook of Counselling Children and Young People (pp. 35-48). London, UK: Sage.

Koren, P.E., DeChillo, N., \& Friesen, B.J. (1992) Measuring em- powerment in families whose children have emotional disabilities: A brief questionnaire. Rehabilitation Psychology, 37, 305-321. doi: 10.1037/h0079106

Krischer, M.K., Trautmann-Voigt, S., Kaspers, S., Voigt, B., Flechtner, H.H., \& Lehmkuhl, G. (2013). Effectiveness of psychodynamic psychotherapy in children and juveniles results of a pilot study. Zeitschrift fur Kinder- und Jugendpsychiatrie und Psychotherapie, 41, 87-97. doi: 10.1024/1422-4917/a000216

Lavanchy Scaiola, C., Favez, N., Tissot, H., \& Frascarolo, F. Family Alliance Assessment Scale (FAAS), version 6.3. (unpublished manuscript).

Lieberman, A.F., Weston, D.R., \& Pawl, J.H. (1991). Preventive intervention and outcome with anxiously attached dyads. Child Development, 62, 199-209. Available from: http://www.jstor.org/stable/1130715. doi: 10.2307/1130715

Lucarelli, L., Ammaniti, M., Porreca, A., \& Simonelli, A. (2017). Infantile anorexia and co-parenting: a pilot study on motherfather-child triadic interactions during feeding and play. Frontiers in Psychology, 8, 1-11. doi: 10.3389/fpsyg.2017.00376

Lundahl, B.W., Tollefson, D., Risser, H., \& Lovejoy, M.C. (2008). A meta-analysis of father involvement in parent training. Research on Social Work Practice, 18, 97-106. doi: 10.1177/1049731507309828

Mazzoni, S., Lavadera, A.L., Di Benedetto, R., Criscuolo, M., Mangano, C. (2015). Le coalizioni genitoriali: Lo stile interattivo del bambino a fronte degli stili cogenitoriali. Psicologia Clinica dello Sviluppo, 19(1), 79-100.

Mazzoni, S., Veronesi, C., \& Vismara, L. (2013). Coordinare la genitorialita nelle famiglie con un bambino con Disturbo dello Spettro Autistico. Psichiatria dell'Infanzia e dell'Adolescenza, 80, 39-60.

Midgley, N., \& Kennedy, E. (2011). Psychodynamic psychotherapy for children and adolescents: a critical review of the evidence base. Journal of Child Psychotherapy, 37, 232-260. doi: 10.1080/0075417X.2011.614738

Midgley, N., O’Keeffe, S., French, L., \& Kennedy, E. (2017). Psychodynamic psychotherapy for children and adolescents: an updated narrative review of the evidence base. Journal of Child Psychotherapy, 40, 1-23. doi: 10.1080/0075417X. 2017.1323945

Montinari, G., \& Pelanda, E. (2012). La relazione adolescentiadulti. Riflessioni psicoanalitiche ed esperienze cliniche. Rome, Italy: Il Pensiero Scientifico.

Oren, D. (2012). Psychodynamic Parenthood Therapy: A model for therapeutic work with parents and parenthood. Clinical Child Psychology and Psychiatry, 17(4), 553-570.

Palmer, R., Nascimento, L.N., \& Fonagy, P. (2013). The state of the evidence base for psychodynamic psychotherapy for children and adolescents. Child and Adolescent Psychiatric Clinics of North America, 22, 149-214. doi: 10.1016/j.chc. 2012.12.001

Parolin, M., Sudati, L., Gatta, M., \& Simonelli, A (2017). Applicazione della procedura del Lausanne Trilogue Play a famiglie con figli adolescenti: uno studio preliminare. Psicologia Clinica e dello Sviluppo (in press).

Pellizzoni, S., Tripani, A., Miscioscia, M., Giuliani, R., \& Clarici, A. (2017) The Use of Lausanne Trilogue Play in Three Cases of Gastroschisis Diagnosed during Pregnancy. Front Psychol, 8, 1-5. doi: 10.3389/fpsyg.2017.00509

Philipp, D., Fivaz-Depeursinge, E., Corboz-Warnery, A., \& Favez, N. (2009). Young infants' triangular communication with their parents in the context of maternal postpartum psy- 
chosis: Four case studies. Infant Mental Health Journal, 30 (4), 341-365. doi: 10.1002/imhj.20218

Pruett, M.K., Pruett, K.D., Cowan, C.P., \& Cowan, P.A. (2017). Enhancing Paternal Engagement in a Coparenting Paradigm. Child Development Perspectives, 0, 1-6. doi: 10.1111/ cdep.12239

Siegel, D. J., \& Hartzell, M. (2003). Parenting from the Inside Out: How a Deeper Self-Understanding Can Help You Raise Children Who Thrive. New York: Penguin.

Simonelli, A., Parolin, M., Sacchi, C., De Palo, F., \& Vieno, A. (2016). The Role of Father Involvement and Marital Satisfaction in the Development of Family Interactive Abilities: A Multilevel Approach. Frontiers in Psychology, 7, 1725. doi: 10.3389/fpsyg.2016.01725

Slonim, D.A., Shefler, G., Slonim, N., \& Tishby, O. (2012). Adolescents in psychodynamic psychotherapy: Changes in internal representations of relationships with parents. Psychotherapy Research, 23, 201-217. doi: 10.1080/ 10503307.2013.765998

Stefini, A., Horn, H., Winkelmann, K., Geiser-Elze, A., Hartmann, M., \& Kronmüller, K.T. (2013). Attachment styles and outcome of psychoanalytic psychotherapy for children and adolescents. Psychopathology, 46, 192-200. doi: $10.1159 / 000341591$

Stern, D. (2004). The present moment in psychotherapy and everyday life. New York: Norton.
Sutton, A., \& Hughes, L. (2005). The psychotherapy of parenthood: Towards a formulation and valuation of concurrent work with parents. Journal of Child Psychotherapy, 31(2), 169-188.

Teubert, D.\& Pinquart, M. (2010). The association between coparenting and child adjustment: A meta-analysis. Parenting: Science and Practice, 10 (4), 286-307.

Thomas, R., Zimmer-Gembeck, M.J. (2007). Behavioral outcomes of parent-child interaction therapy and triple p-positive parenting program: A review and meta-analysis. Journal of Abnormal Child Psychology, 35(3), 475-495. doi: 10.1007/s10802-007-9104-9

Tissot, H., Favez, N., Frascarolo, F., \& Despland, J.N. (2016). Coparenting Behaviors as Mediators between Postpartum Parental Depressive Symptoms and Toddler's Symptoms. Front Psychology, 7, 1-9. DOI: 10.3389/fpsyg.2016. 01912.

Tronick, E., \& Cohn, J. (1989). Infant-mother face-to-face interaction: Age and gender differences in coordination and the occurrence of miscoordination. Child Development, 60, 85-92.

Tsiantis, J., Boethious, S., Hallerfors, A., Horne, A., \& Tischler, L. (2000). Working with Parents: psychoanalytic Psychotherapy with Children and Adolescents. London: Karnac. 